\title{
SOURCES OF NATURAL BACKGROUND RADIATION
}

\author{
Nicolay Todorov DOLCHINKOV, Chief Assistant Prof. PhD \\ n_dolchinkov@abv.bg \\ „Vasil Levski“ National Military University, Veliko Tarnovo, Bulgaria, Department "IPA"
}

\begin{abstract}
After the major accidents in "Chernobyl" NPP, located on the territory of present-day Ukraine, and then in the USSR in April 1986, in Bulgaria, as well as in most European countries a lack of systems for a continuous measurement of gamma radiation was reported, which have to provide reliable real-time information on radiation status. Consequently, in the European Union, construction of automated systems for continuous monitoring of gamma radiation has begun. Observations on the state of the radiation background in Bulgaria are carried out in parallel in two ways. A serious problem can cause people to cross a state border in random unregulated places and not at a checkpoint.
\end{abstract}

Key words: radiation safety, background, nuclear, monitoring, ionising radiation

Radioactivity or even radioactive decay is the ability of atomic nuclei of unstable isotopes of chemical elements to spontaneously turn into nuclei of other chemical elements that emit energy in the form of particles or electromagnetic radiation - for example, alpha particles, beta-particles or gamma rays.

Radioactive contamination is a permanent radioactive particulate matter, mostly due to a nuclear explosion. These particles pass through the atmosphere from the explosion and then fall to the ground. They fall into the soil, water and air and lead to radioactive contamination of the environment. Especially dangerous for humans is radioactive waste with radioactive isotopes of iodine, strontium and cesium. Iodine accumulates in the thyroid gland, strontium - in the bones, 
and cesium - in the muscles, which is why the human organism undergoes continuous internal radioactive irradiation.

Radiation pollution is of current national and international significance and is related to increasing measures to prevent accidents resulting from the use of nuclear energy for peaceful purposes and in military affairs. In view of the increased activity of terrorist organisations and the unstable situation in the region, the likelihood of nuclear terrorism has increased. According to Dolchinkov (2016), because of its geopolitical location, the nuclear power plants operating in Bulgaria and in a country close to us can have a great impact on the surrounding natural radioactive background. Optimising and managing existing radiation monitoring systems will lead to increased nuclear security in Bulgaria and adequate measures and decision making to improve the protection of the population from radiation exposure as a result of changes in the natural radioactive background.

The article explores the parameters for measuring the radiation background, the effectiveness of the existing radioactive pollution monitoring systems, the way of collecting information and its processing. Systems analysis has been made, factors influencing the radioactive background have been considered, measures are proposed to optimise the choice of meteorological elements and monitoring stations that will lead to better operation of the existing radionuclide monitoring system.

The degree of risk and the threat to National security in the increase of the radiation background as a result of a nuclear accident or nuclear terrorism, depending on different climatic and political factors, is assessed. A model of a sophisticated system for complex assessment of environmental radiation indicators has been proposed.

The systematic approach will be used to solve the research tasks. It will be implemented in the following aspects:

- system-element - revealing the reasons for increasing the natural radioactive background, their characteristics and classification, the elements and the dynamics of their development;

- system-structured - revealing causality and interrelationships between different meteorological, climatic and geopolitical factors; 
- system-functional - revealing elements that are in correlation with the planning and management of the radiation background monitoring system.

Methods such as analysis, synthesis, analogy and comparison, analysis of expert opinions, etc. were used in the course of the research.

Worldwide, countries such as the USA, Russia and Japan have the greatest experience in the area concerned, but the documents governing these activities at national level are confidential and not accessible to the general public. This fact once again confirms the relevance of the current work, in which it is precisely the optimisation of the current systems for monitoring the indicators determining the presence of radioactive contamination, taking timely measures and notifying the respective institutions for the purpose of taking preventive measures.

In this aspect, the purpose of the work is defined, namely, the analysis of the factors influencing the natural radioactive background and the measures to be taken in its enhancement, the optimisation of the monitoring and publicity systems for the radioactive pollution of the environment, and identifying opportunities to increase its effectiveness.

After detection of radioactivity in the early years of the century, scientists believed that the source of radioactive emissions into the atmosphere were only earth and rocks. Very soon, however, it was noted that with the increase in altitude (in experiments with balloons), the radioactive radiation increased due to cosmic radiation. Later, it was found that cosmic radiation contains two components: primary radiation - of galactic origin penetrating the atmosphere, and secondary cosmic radiation - derived from the reaction of cosmic rays with the nuclei of elements in the air, space dust, which is layered on the planet and others. This activity is mainly driven by the light radionuclides, such as: beryllium, sodium, aluminum, vanadium, etc. Cosmic rays that reach the Earth's surface can create radioisotopes decay but, compared to other naturally occurring radionuclides, is extremely low and not particularly important.

Dolchinkov and Nichev (2016) maintain that with the importance of a biological standpoint, these are formed in the atmosphere of carbon-14 and tritium. Carbon-14 is formed by irradiation with neutrons, nitrogen-14, and the three - of hydrogen. Radio hydrocarbon included in the organic world follows the path of a stable isotope and it helps to learn a number of processes, such as photosynthesis, 
decomposition of organic matter, determining the age of organic formations and others. It passes in coal, oil, etc., and also in inorganic carbon compounds (carbonates) and others. Triturate is also mixed with hydrogen in water, and other organic compounds, which enters as a component and is involved in the circulation of the substances, but its half-life is much shorter. Much of tritium and carbon-14 accumulates in ocean waters.

The natural radioactive background in which people live is built by the radioactivity of the various components of the environment. Some reflection on it is given by the buildings and the production conditions. This is not about companies which work with radioactive materials, radiation, or produce such using nuclear energy and others that make up the artificial radioactive background (Quarterly bulletin on the state of the environment for the period July-September 2014 of the EEA). For the natural radioactive background, except for potassium, uranium, radium and thorium and their products, radon and thorium are also of great value. Bonchev argues that for a long time, the latter weren 't given importance in the evaluation of human irradiation, as they are short-lived alpha emitters, inert gases, which are not included in the exchange of living organisms, but their constant presence in the surrounding air leads to exposure of the trachea and alveoli. It was found that their relative involvement in human exposure is significant (Fig. 1).

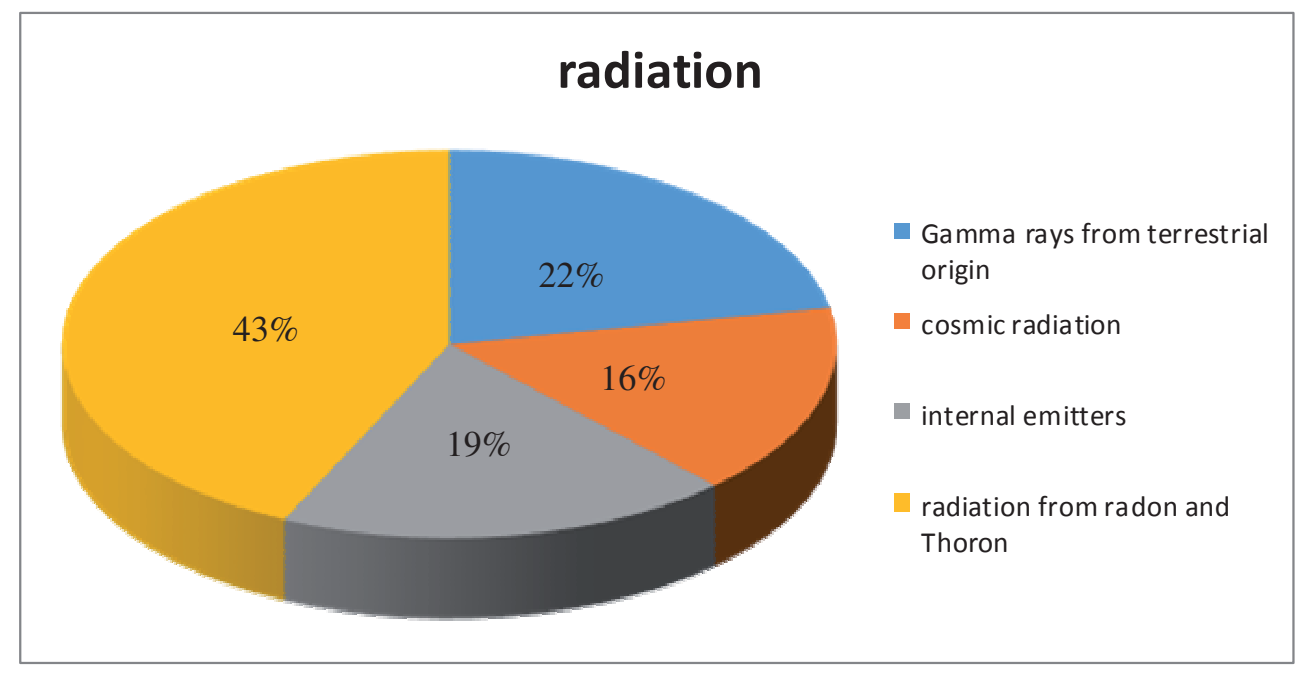

Figure 1. Relative participation of different components of the natural radioactive background in the irradiation of the population. 
Over the past 5 years, even a programme for the study of radon content in school and the building has been funded partly by the EU («Бюлетин за гама-фона в Република Бъмгария на АЯР», 2015).

The average effective radiation dose per inhabitant of the planet is $2000 \mathrm{~Sv}$ per year. Residents in some regions, cities, and countries, however, have significant differences in the dose they absorb. For example, citizens of the town of Guajajara in Brazil receive 26 times more the dose of radiation than those of Europeans per hour, or for every hour on the beach of this town visitors receive 250 times more radiation from thorium, radon and daughter products than in Naples or the Black Sea (Годишник за състоянието на околната среда в Република Бъцгария 1992, 1993) (Fig. 2).

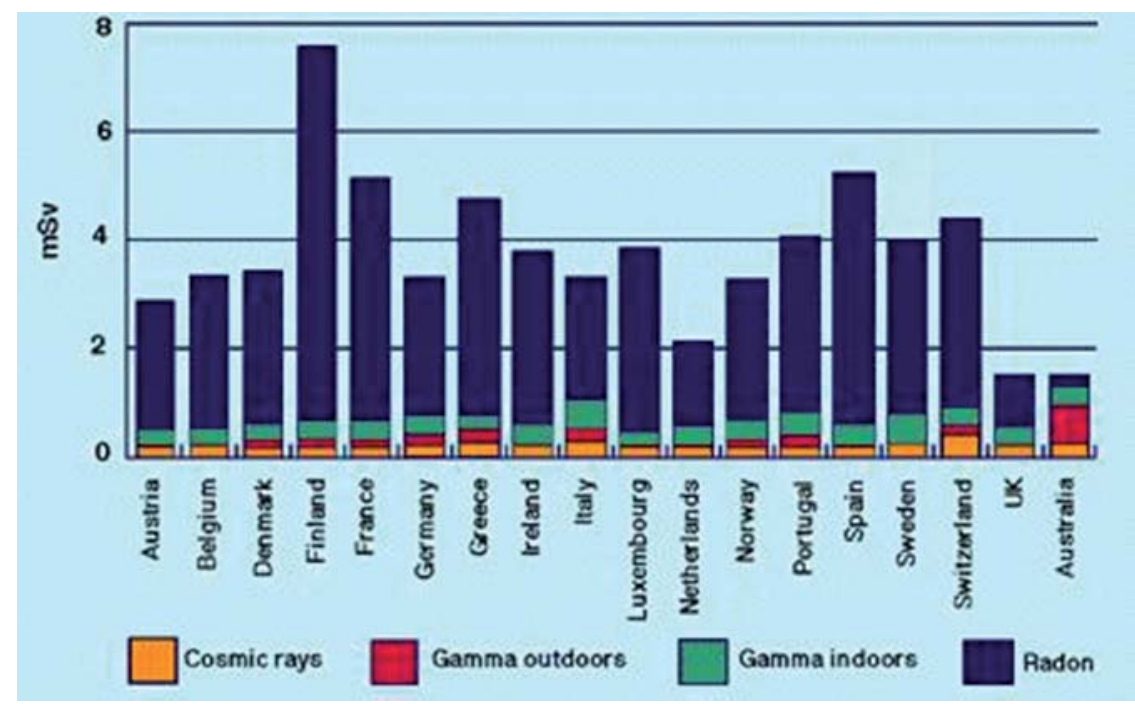

Figure 2. Doses of radiation from natural sources in various countries

Dolchinkov and Haralampiev (2014) state that in nature, there are many minerals, plants and even animals that have natural radiation. Studies show that natural radiation intensity is different and depends on the composition of the bedrock on which the given territory is. At the same time, in the world and in our country, there are areas of high natural background radiation, inhabited by people with no visible signs of negative radiation impact. These areas are risky for habitation for the simple reason that the smallest radiation provoked by human activity may 
increase radiation above the limit concentrations. This phenomenon is observed in the vicinity of developed uranium fields and mines producing radioactive minerals. Some mineral springs in Bulgaria have high natural background radiation. Under existing regulations, they must be, captured and free flow of water and its use for watering restricted. Vassilev (2005) maintains that the application of such water for medical purposes must also be done under strict control. In areas with high natural background radiation, the use of pesticides should also be very carefully monitored and after preliminary studies. It is known that some pesticides often contain traces and even larger amounts of radioactive elements or other compounds, which under certain conditions may react with a third substance and cause contamination. Earth, water, air, plants and animals contain over 40 natural radioactive elements mainly in a non-active state. The number of artificial radioactive elements is much higher. Their types and quantities vary and grow, which is associated with the development of the nuclear industry, atomic and nuclear explosions, peaceful aspects of the use of nuclear energy in science, the national economy, medicine etc.

\begin{tabular}{|l|l|l|l|l|l|}
\hline Radionuclides & $\mathbf{T} \mathbf{1} \mathbf{2}$ & Rocks, soils & Air & Water & Human body \\
\hline Uranium - 238 & $4,49 \cdot 10^{9}$ years & + & & & + \\
\hline Uranium - 235 & $7,13 \cdot 10^{8}$ years & + & & & \\
\hline Radium - 226 & 1602 years & + & & & + \\
\hline Radon - 222 & 3,82 days & & + & + & + \\
\hline Polonium - 218 & 3,05 minutes & & + & & + \\
\hline Lead - 214 & 26,8 minutes & & + & & + \\
\hline Bismuth - 214 & 19,7 minutes & & + & & + \\
\hline Lead - 210 & 21 years & + & + & + & + \\
\hline Bismuth - 210 & 5,01 days & & + & & + \\
\hline Polonium - 210 & 138,4 days & + & & & \\
\hline Thorium - 232 & $1,41.10^{10}$ years & + & & & + \\
\hline Radium - 228 & 5,8 years & + & & & + \\
\hline Actinium - 228 & 6,13 hours & + & & & + \\
\hline Taron - 220 & 55 seconds & & + & & + \\
\hline Lead -213 & 10,6 hours & + & + & & + \\
\hline Gallium - 208 & 3,1 minutes & + & + & & + \\
\hline Potassium - 40 & $1,26.10$ years & + & & + & + \\
\hline Carbon - 14 & 5730 years & + & + & + & + \\
\hline Tritium - 3 & 12,3 years & & + & + & + \\
\hline Rubidium - 87 & $6,15.10^{10}$ years & & & + & \\
\hline Sodium - -22 & 2,63 years & & + & + & + \\
\hline Beryllium - 7 & 53,6 days & & + & + & + \\
\hline
\end{tabular}

Table 1. Main natural radionuclides in the environment and the human body 
Natural radioactive elements have also undergone changes since the creation of the planet, when radioactivity was higher. Thus, throughout its existence, the Earth has been immersed in the cosmos and its radioactive emissions that determine the radioactive background, accompany life from its inception and development to the present day.

Important natural radionuclides in the biosphere and our environment can be judged in Table 1. Radioactive elements contained in the Earth's core can be divided into two groups:

1. Elements of the radioactive lines relating to successive transformations;

2. Separate unrelated elements.

The elements of the first group originate from the heaviest isotope ancestor of the radioactive family and its subsidiary products, which by successive decays reach a stable isotope. In nature, the most important are thorium-232 to lead-208. Natural lead contained in these different ratios of its isotopes, such as lead-208, occupies $51.55 \%$, lead-207 is $20.8 \%$ and lead-206 is $26.26 \%$ of the isotope mixture (Krasyuk 2012). Lead has another isotope (Pb-204), whose origin is not fully understood.

Fig. 3 shows the uranium-238 family and its radioactive transformations (Антонов В. А. и колектив 2006, р. 385 - 391). As well as from the Earth, atomic radiation is also emitted from space. There is a constant flow of cosmic rays on the planet. Some of them are retained by the Earth's magnetic field, but a significant part penetrates into the stratosphere where it collides with atomic nuclei of nitrogen and converts to carbon - 14. Other nuclear reactions with oxygen, hydrogen, carbon and others lead to the formation of tritium (3H), beryllium-7, sodium22, and the like. Primary cosmic particles collapse into protons, neutrons, and mesomes with enough energy to form new radionuclides from stable isotopes. Together with the other particles, they reach the surface of the Earth and increase the natural background of the atomic radiation on the planet.

The primary cosmic particles of protons, neutrons, and us-mezopi have enough energy to form new radionuclides from stable isotopes. Together with other particles, they reach the Earth's surface and enhance the natural background of atomic radiation on the planet. 


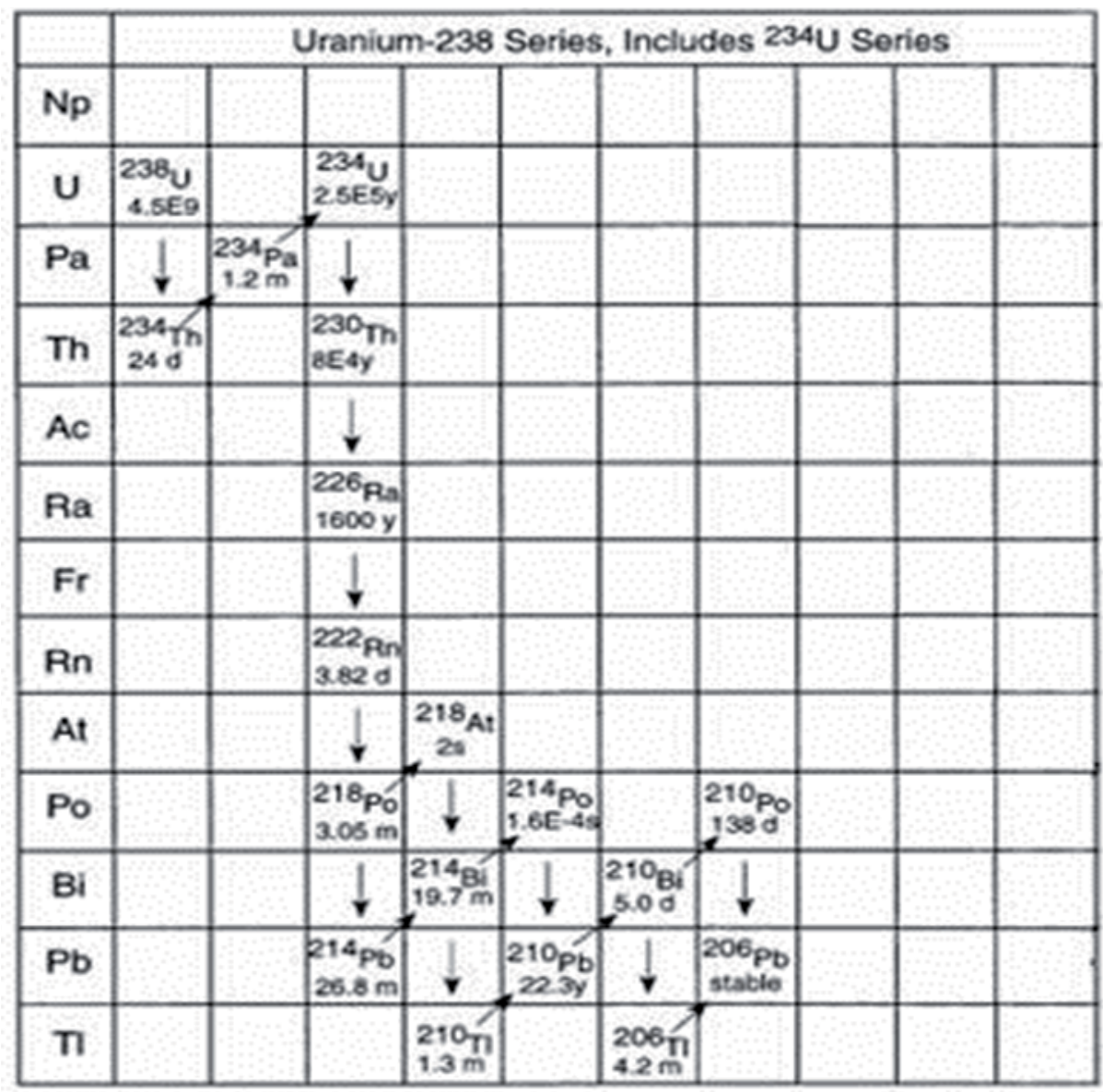

alpha decay: " beta docay, hat ide $(d=$ days; $m=$ minutes; $s=$ seoonds; $y=y$ years)

Figure 3. The family of uranium-238 and its radioactive transformations

\section{Characteristics of solar radiation}

Vassilev (2005) maintains that after detection of radioactivity in the early years of the century, scientists believed that the source of radioactive emissions into the atmosphere was only earth and rocks. Very soon, however, they noticed that with the increase in altitude (in experiments with balloons), radioactive radiation increased due to cosmic radiation. Later, it was found that cosmic radiation is made up of two components: primary radiation - of galactic origin penetrating the atmosphere, and secondary cosmic radiation - derived from the reaction of 
cosmic rays with the nuclei of elements in the air, space dust, which is postponed on the planet etc. This activity is mainly driven by the light radionuclides, such as: beryllium, sodium, aluminum, vanadium etc. Cosmic rays that reach the Earth's surface can create radioisotopes but their radioactivity compared to other radionuclides with natural origin is extremely low and not particularly important.

The most important from a biological standpoint are, thus, carbon-14 and tritium formed in the atmosphere. Carbon-14 is formed by irradiation with neutrons of nitrogen-14, and tritium from hydrogen. Radium hydrocarbon, included in the organic world, follows the path of a stable isotope and it helps to learn a number of processes, such as photosynthesis, decomposition of organic matter, determining the age of organic formations etc. It passes in coal, oil, etc., and also in the inorganic carbon compounds (carbonates) and others. Tritium is also mixed with hydrogen in water, organic and other compounds, in which it is included as a component and is involved in the circulation of the substances, but its half-life is much shorter. Much of tritium and carbon-14 accumulates in ocean waters.

It is believed that the content of radioactive elements is the result of nuclear reactions in the atmosphere and, in recent years, 1000 are constantly present in it. Naturally, it is not a question of radionuclides as a result of the testing of nuclear weapons and other human activity, but natural cosmogenic radionuclide. There is interest in the established dependence on the content of radionuclides in the atmosphere, not only by the altitude but also the latitude of the Earth. It was found that the intensity of cosmic radiation increases with the distance from the equator to the north. That is banded with the influence of magnetic fields on the planet.

\section{Characteristics of radiation in the surface layer of the atmosphere}

Radioactivity in ground air is mainly driven by thoron and radon and their progenies (radon is a progeny of radium and thoron - thorium. These gases are emitted by rocks, soils, and watersheds. According to Vassilev, radon from 
$2 \times 10-10 \mathrm{ci} / \mathrm{l}$ in the soil air decreases in the atmospheric air over the ocean with a distance from shore of 1 x 10-15 Ci /l (Василев 2005).

Coming out of the ground into the atmosphere, radon and thoron also decompose and produce different numbers of short-lived isotopes. Generally, the amount of these isotopes in the atmosphere is determined by different conditions: content in rocks and soils, altitude, winds, temperature, precipitation (rain, snow, etc.), season, soil temperature etc. Special monitoring of the content of radon and thoron in the soil air from A.A. Krasyuk and B.A. Krasyuk found that the content of radium in the soil air is on average 2,000 times higher than in the air, and the highest emanation is from granite soils and the lowest - sandy (National report on the status and protection of the environment in Bulgaria in 2014 of the EEA) in the same soil, emanation can fluctuate significantly depending on rainfall, sunshine, temperature, wind, depth of horizon etc. Baranov summarised studies on the natural radioactive elements in the soil and soil air by setting the emanation coefficient of different soil types, soil horizons, humus content and more. A significant impact on reducing the concentration of radon and a progeny has been made by air and temperature inversions and movement. The winds, especially from the oceans or other bodies of water, dilute radioactivity. It was found that in the winter, in comparison with the summer months, the concentration of radon is a dozen times lower. These concentrations vary repeatedly (3-5 times) and in the day, they decrease in the afternoon compared to the morning.

There have been differences in buildings built of stone, bricks, and cement with those of wood due to different ventilation conditions.

Usually in buildings and homes with poor ventilation, more radon and daughter products are contained in the air than outdoors. Thus, on some islands in the ocean (Hawaii, the Philippines, etc.), the content of radon in the air is $1-4.10^{-12}$ $\mu \mathrm{Ci} / \mathrm{m}^{3}\left(0,037-0,15 \mathrm{~Bq} / \mathrm{m}^{3}\right)$, but in Washington $4,4 \mathrm{~Bq}$ or $0,12 \mathrm{pCi} / \mathrm{cm}^{3}$. From the standpoint of large groups of the population, the level of radiation outside buildings is more important than that in buildings, because in them it depends on construction materials, and on weakening due to external radiation passing through walls etc.

Survey results from the third quarter of 2014 show that the radiation background in the controlled posts is within the range of a typical natural background for the 
post and meteorological conditions (Figure 4) (Quarterly bulletin on the state of the environment for the period July-September 2014 of the EEA).

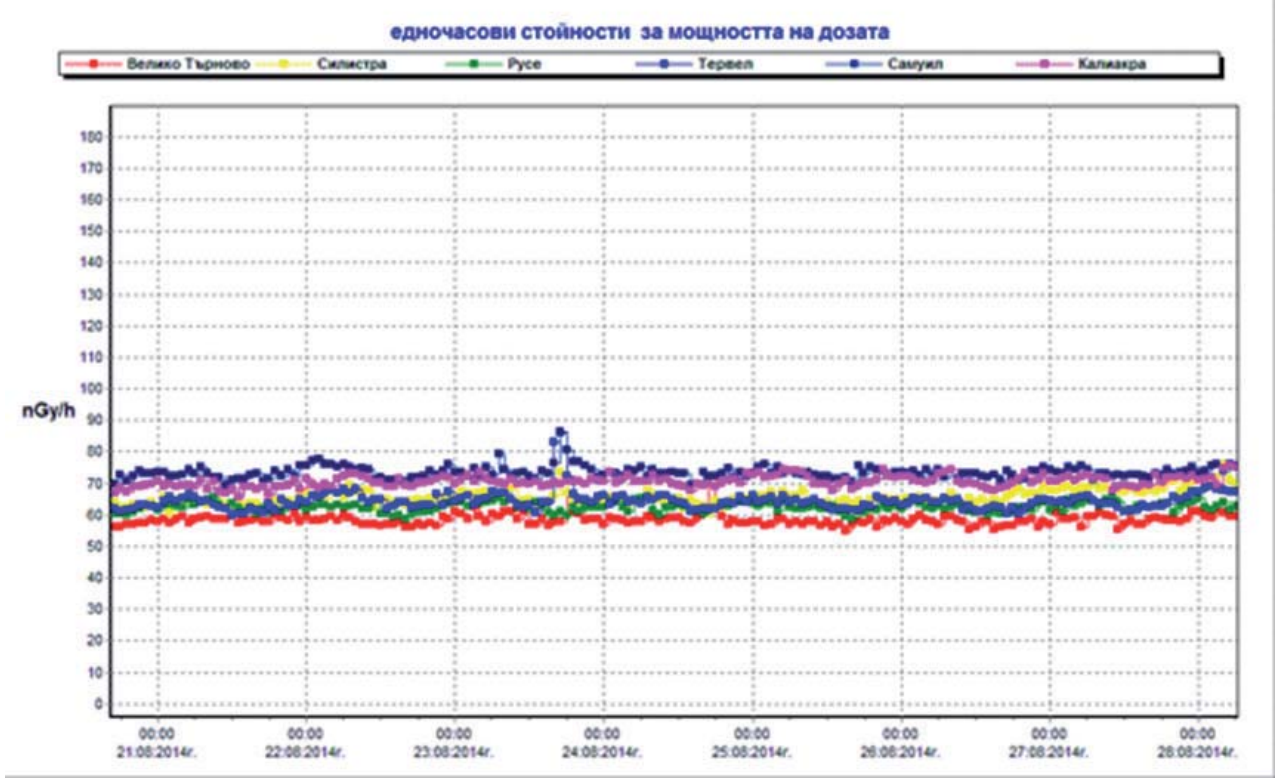

Figure 4. Average hourly dose rate, $(n G y / h) 6$ Local Monitoring Stations for the period 21.08. - 27.08.2014

\section{Conclusions}

1. The most highly radioactive isotopes spread into the atmosphere. For the natural radioactive background, except for potassium, uranium, radium and thorium and their products, radon and thorium are also of great value.

2. Earth, water, air, plants and animals contain over 40 natural radioactive elements mainly in a non-active state. The number of artificial radioactive elements is much higher.

3. Survey results from the third quarter of 2014 show that the radiation background in the controlled posts is within the range of a typical natural background for the post and meteorological conditions 


\section{References}

Антонов, В. А. и колектив, 2006. Екология, Военна екология. ИзАателски комплекс „Камертон“, Москва - Смоленск.

«Бюлетин за гама-бона в Република България на АЯР», 2015, София.

Bonchev, Tsv., Tsankov L. and others, 1997. Directory of radionuclides characteristic of the NPP, Tita Consult, Sofia.

Аолчинков, Н., Радиационната безопасност в Бъцгария, 2016. Научна конференция „Радиационната безопасност в съвременния свят“ НВУ „В. Аевски“- гр. В. Търново - 11 ноември 2016.

Dolchinkov, N. T. and Haralampiev, M. S., 2014. Characteristic of radiation from the earth bowels, "V. Levski” NMU, Veliko Tarnovo.

Dolchinkov, N. T. and Nichev, N. B., 2016. Characteristics of radiation. Revista academiei fortelor terestre „Nicolae Bãlcescu“ 2(82), Sibiu.

Годишник за състоянието на околната среда в Република България 1992, 1993. Министерство на околната среда и водите, София.

Krasyuk, A.A., 2012. Soils and gee doped in nature. Selyhozgiz, Moscow.

National report on the status and protection of the environment in Bulgaria in 2014 of the EEA.

Quarterly bulletin on the state of the environment for the period July-September 2014 of the EEA.

Vassilev, G., 2005. Radioecology, Tita Consult, Sofia./Васимев, Г., 2005. Радиоекология. Тита консулт, София. 